\title{
SENSITIVITY OF COMMON BACTERIAL PATHOGENS CAUSING PNEUMONIA IN CHILDREN AGE 1 MONTH TO 5 YEARS.
}

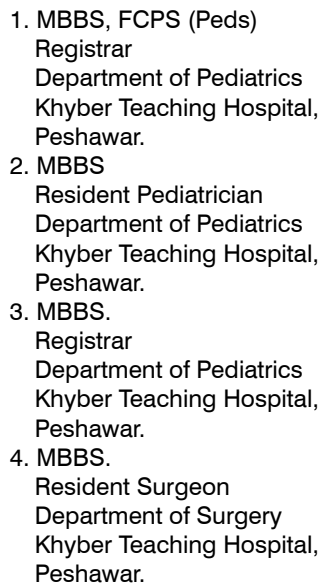

Correspondence Address: Dr. Rifaq Zeb

Room No.49, Old Doctor Hostel, Khyber Teaching Hospital, Peshawar. rifaqzeb@hotmail.com

Article received on: 31/10/2018

Accepted for publication: 25/02/2019

Received after proof reading:

28/08/2019
Farman Ali ${ }^{1}$, Rifaq Zeb ${ }^{2}$, Farid Ullah ${ }^{3}$, Junaid Zeb ${ }^{4}$

ABSRACT... Background: Pneumonia is defined as inflammation of lung parenchyma. Aim of the current study was to identify the culture and sensitivity of bacteria causing pneumonia in one month to 5 years of age. Study Design: Cross sectional study. Setting: Department of Pediatric Medicine, Khyber Teaching Hospital (KTH), Peshawar. Period: December 2016 to March 2018. Material \& Methods: Total 292 patients were randomly included in study. Data were collected by pre designed Performa and analyzed by SPSS 21. Results: Mean age of patients was $2.7 \pm 1.2$ years. Male to female ratio was 3:2. Culture report showed $123(42.1 \%)$ were Staphylococcus Aureus positive, $87(29.8 \%)$ streptococcus pneumonia, $75(25.7 \%)$ Hemophilus Influenza, 3(0.01\%) Pseudomonas aeruginosa, 2(0.0068\%) Klebsiella pneumoniae, 2 (0.0068\%) E.coli positive. All the bacteria were sensitive to commonly used antibiotics unless we observed resistance of $\mathrm{H}$. Influenza against clarithromycin and Co amoxiclav. In rest of seven cases, out of total two cases of $\mathrm{E}$. coli both were sensitive to amikacin while resistance to amoxil and co amoxiclave. Out of total three pseudomonas cases, two cases were resistance to ceftriaxone and amoxil, one was sensitive to ceftriaxone, while all three were sensitive to amikacin, two cases were of klebsiella pneumonia and both of them were sensitive to amikacin while resistant to amoxil. Conclusion: Most common organism causing pneumonia in one month to 5 years of age is $\mathrm{S}$ aureus followed by $\mathrm{S}$ pneaumoniae, $\mathrm{H}$ influenza, Paurogenosia, klabsiella and E.coli. Most of these organisms were sensitive to amoxil, ampiclox, cefotaxime and ceftriaxone while resistance of $\mathrm{H}$ influenza was observed to clarithromycin and co amoxiclave.

Key words: $\quad$ H Influenza, Pneumonia, Sensetivity, S Aureus, S Pneaumoniae.

Article Citation: Ali F, Zeb R, Farid Ullah, Zeb J. Sensitivity of common bacterial pathogens causing pneumonia in children age 1 month to 5 years. Professional Med $\mathrm{J}$ 2019; 26(9):1393-1397. DOI: 10.29309/TPMJ/2019.26.09.435

\section{INTRODUCTION}

Pneumonia is defined as inflammation of lung parenchyma in which the effected parts alveolar space filled with exudate, inflammatory cells and fibrin. Mostly it is caused by bacteria and viruses but chemicals, trauma other infectious agents like fungi and yeast can also cause them. ${ }^{1}$ Incidence of pneumonia in the developing countries is 0.280 episode per child year much higher than developed countries in which it is $0.026 .{ }^{2}$ Acute Respiratory Infections (ARIs) is a common cause of mortality below 5 years of age in low socioeconomic countries and most deaths that is from ARls is caused by severe pneumonia. . $^{3,4,5,6}$ many factors like malnutrition, improper vaccination, poor hygiene and late presentation to health facility can lead to high mortality. ${ }^{7}$
Pneumonia is most commonly caused by streptococcus pneumoniae (S pneumoniae) that accounts for upto $50 \%$ cases followed by Haemophilus Influenza type b ( $\mathrm{H}$ influenza) and staphalococcus aureus (S. aureus). ${ }^{8}$ Different guidelines are issued by World Health Organization, ${ }^{9}$ British Thoracic Society ${ }^{10}$ and Infectious Diseases Society of America ${ }^{11}$ regarding pneumonia and its management. These guidelines suggest amoxicillin and cephalosporin as first line antibiotics to treat pneumonia keeping in view the common organism (S. Pneumoniae). Oral antibiotics is preferred than IV until there is severe pneumonia. ${ }^{9}$

The aim of the study is to identify the culture and sensitivity of bacteria causing pneumonia, in order to know the resistance and sensitivity of 
involved bacteria's, this will lead to proper use of antibiotics, lower the expenses and improvement in health and thus will decrease mortality and morbidity.

\section{MATERIALS AND METHODS}

This Descriptive Cross sectional study was done in Department of Pediatric Medicine, Khyber Teaching Hospital (KTH), Peshawar from December 2016 to March 2018. Total 292 patients who had culture proved pneumonia (after 48hrs) presented to the emergency pediatric service, OPD or pediatric wards from one month to 5 years of age and both gender were randomly recruited to the study. Those who have aspiration pneumonia, developmentally delayed, syndromic and history of any antibiotic used in last week were excluded from study.

After taking informed consent from their parents or caregiver, name, age, sex and record numbers was taken and recorded on predesigned performa. Detailed history including history of antibiotic use in the last week was taken from their parents or caregiver. Examination was done in detail. Chest $x$ ray was done in radiology department of KTH. Data was collected by Non probability consecutive sampling technique and analyzed using SPSS 21 . The quantitative variables like age, weight were presented by calculating mean and standard deviation. The qualitative variables like gender and bacteria (S aureus, $\mathrm{H}$. influenza, $\mathrm{S}$ pneumonia.) causing pneumonia were presented by calculating frequency and percentages. Antibiotic sensitivity is stratified among age and gender to see effect modifiers. Results are presented in the form of paragraphs and tables.

\section{RESULTS}

Out of total study population, who have blood culture proven pneumonia were tested for antibiotic sensitivity, mean age and standard deviation was $2.7 \pm 1.2$ years. $176(60.3 \%)$ were male and $116(39.7 \%)$ were females, with male to female ratio was 3:2. Among them 123(42.1\%) were Staphylococcus Aureus, 87(29.8\%) were streptococcus pneumonia, 75(25.7\%) were Hemophilus Influenza, 3(0.01\%) were Pseudomonas aeruginosa, 2(0.0068\%) were Klebsiella pneumoniae, $2(0.0068 \%)$ were E.coli.

Regarding the antibiotic resistance or sensitivity pattern of common bacteria, we found that all the bacteria were sensitive to commonly used antibiotics unless we observed resistance of $H$. Influenza against clarithromycin and Co amoxiclav. We also found some bit of resistance of streptococcus pneumoniae against co amoxiclav and some for staph aureus against the same drug. Staph Aureus also showed some bit of resistance against amoxil and ampiclox detail given in Table-I.

In other seven cases, out of total two cases of E. coli both were sensitive to amikacin while resistance to amoxil and co amoxiclave. Out of total three pseudomonas cases, two cases were resistance to ceftriaxone and amoxil, one was sensitive to ceftriaxone, while all three were sensitive to amikacin, two cases were of klebsiella pneumonia and both of them were sensitive to amikacin while resistant to amoxil.

\begin{tabular}{|l|c|c|c|c|c|c|}
\hline \multirow{2}{*}{ Type of Antibiotic } & \multicolumn{2}{|c|}{ Staphylococcus Aureus } & \multicolumn{2}{|c|}{ Streptococcus Pneumoniae } & \multicolumn{2}{c|}{ Hemophilus Influenza } \\
\cline { 2 - 6 } & Sensitive & Resistant & Sensitive & Resistant & Sensitive \\
\hline Amoxil & $95(77.2 \%)$ & $28(22.8 \%)$ & $80(91.9 \%)$ & $7(8.1 \%)$ & $70(93.3 \%)$ \\
\hline Ampiclox & $101(82.1 \%)$ & $22(17.9 \%)$ & $81(93.1 \%)$ & $6(6.9 \%)$ & $66(88 \%)$ & $9(12 \%)$ \\
\hline Cefotaxime & $110(89.4 \%)$ & $13(10.6 \%)$ & $74(85.1 \%)$ & $13(14.9 \%)$ & $59(78.7 \%)$ & $16(21.3 \%)$ \\
\hline Ceftriaxone & $117(95.1 \%)$ & $6(4.9 \%)$ & $83(95.4 \%)$ & $4(4.6 \%)$ & $72(96 \%)$ & $3(4 \%)$ \\
\hline Amikacin & $79(64.2 \%)$ & $44(35.8 \%)$ & $78(89.7 \%)$ & $9(10.3 \%)$ & $68(90.7 \%)$ & $7(9.3 \%)$ \\
\hline Clarithromycin & $94(76.4 \%)$ & $29(23.6 \%)$ & $83(95.4 \%)$ & $4(4.6 \%)$ & $40(53.4 \%)$ & $35(46.6 \%)$ \\
\hline Co Amoxiclav & $99(80.5 \%)$ & $24(19.5 \%)$ & $65(74.7 \%)$ & $22(25.3 \%)$ & $54(72 \%)$ & $21(28 \%)$ \\
\hline
\end{tabular}




\section{DISCUSSION}

Pneumonia is a common cause of death in children under five years of age, it is very important to timely manage the disease in order to decrease mortality and morbidity. Antibiotic resistance and sensitivity is an important problem that we are facing. Literature shows very few local studies regarding resistance and sensitivity of antibiotic in pediatric age group, current study focused on common organisms causing pneumonia and their resistance and sensitivity in order to use proper antibiotics. Resistance is a terrible situation for both doctor and patient. Doctor should know the susceptibility pattern while prescribing the antibiotics.

Current study showed that common organism involve in pneumonia is $\mathrm{S}$. aureus followed by S.Pneumonae and $\mathrm{H}$. influenza. This study also demonstrated variable antibiotic sensitivity pattern of the identified microorganisms to commonly used antibiotics even though few of them are recommended first-line antibiotic for treatment of severe pneumonia in children. ${ }^{12}$

Various studies that is done in low socio economic countries showed $S$ Pneumoneae is the common organism causing pneumonia. ${ }^{13-15} \mathrm{~S}$ aureus is common in malnourished children and malnourishment is common in our country so therefore it is common in our set up. ${ }^{16}$

Although we selected all blood culture proven pneumonia in our study but blood culture is less commonly positive in pneumonia. According to Falade AG et al, blood culture is only positive in eighteen present of cases. ${ }^{17}$ while study of Kabara SK revealed that blood culture is positive in five to fifteen percent of cases. ${ }^{18}$

Our study shows that strep. Pneumonia is mostly sensitive to amoxicillin cefotexime and co amoxiclave. Study of Ali that is done in Punjab also show similar results in which strep pneumonia is mostly sensitive to cefotaxime. amoxicillin and co amoxi clave. ${ }^{19}$

The other seven cases, among them both cases of E. coli were sensitive to amikacin while resistance to amoxil and co amoxiclave, two cases of pseudomonas were resistance ton ceftriaxone and amoxil, one were sensitive to ceftriaxone, while all three were sensitive to amikacin, both cases of klebsiella pneumoniae were sensitive to amikacin while resistant to amoxil. This is similar to the study of Ali et all in which klebsiella is 97.37\% sensitive to amikacin while pseudomonas aeruginosa were $80 \%$ sensitive to amikacin, ${ }^{19}$ but these are small number of case, upon which cannot say their proper sensitivity and resistant to particular antibiotics, further studies should be needed to determine the sensitivity and resistance of these bacteria.

Most pneumonia guidelines recommend amoxicillin for the first-line therapy in children less than 5 years of age and macrolides in children older than 5 years of age..$^{20-24}$ The simple use of macrolides in children of all ages, on the other hand, can no longer be recommended as the worldwide resistance to macrolides among S. pneumoniae is high, approximately $35 \% .^{25}$ The most recently published expert opinion on pneumonia management recommends amoxicillin for all children with pneumonia without co-morbidity. ${ }^{26}$ Addition of macrolide therapy is suggested only if no clinical improvement is observed after 48 hours treatment with amoxicillin.

Management guidelines are only directional and the choice of empiric antibiotic therapy should be based on the patient's age, clinical presentation, local resistance pattern of predominant bacteria, and local epidemiologic factors. ${ }^{21,22,26}$, For example, amoxicillin is always the first-line therapy if $S$ pneumoniae is thought to be the likely pathogen, and macrolides should be used if atypical bacteria are suspected. ${ }^{20}$ Secondary antibiotic choices in outpatient care include phenoxymethylpenicillin (penicillin V), cefaclor, amoxicillin/clavulanate, co-trimoxazole, and doxycycline in children older than 8 years of age.

\section{CONCLUSION}

Common bacterias causing pneumonia in one month to 5 years of age is $S$ aureus followed by $\mathrm{S}$ pneaumoniae, $\mathrm{H}$ influenza, $\mathrm{P}$ aurogenosia, klabsiella and E.coli. Most of these bacteria's were 
sensitive to amoxil, ampiclox, cefotaxime and ceftriaxone while resistance of $\mathrm{H}$ influenza was observed to clarithromycin and co amoxiclave. Some bit resistance of $S$ aureus and $S$ pneumoniae also found toward co amoxiclave. $P$ aeuroginosa, klabsiella and $E$ coli were sensitive to amikacin while much resistance of $P$ aeurogenosia and $E$ coli was found to amoxil and ceftriaxone.

Copyright@ 25 Feb, 2019.

\section{REFERENCES}

1. Stedman's medical dictionary. 27th ed. Baltimore, Md: Lippincott, Williams and Wilkins; 2003.

2. Sectish TC, Thomas SJ. Community acquired pneumonia. In: Kliegman RM, Bonita M.D. Stanton, MD, St. Geme J, Schor N, Behrman RE, editors. MDNelson Textbook of Pediatrics. 19th ed. 2008.p.4387.

3. UNICEF. Pneumonia: The forgotten killer of children. The United Nations Children's fund (UNICEF)/ World Health Organization (WHO). [Online]. [Cited on April 11, 2006]. Available from URL: http://www.unicef.org/ publications/index_35626.html.

4. Schuchat A, Dowell SF. Pneumonia in children in the developing world: new challenges, new solutions. Semin Paediatr Infect Dis. 2004; 15:181-9.

5. Igo R, Cynthia BP, Zoruka B. Epidemiology and aetiology of childhood pneumonia. Bull WHO. 2008; 88:321-416.

6. Djelantik IG, Gessner BD, Sutanto A, et al. Case fatality proportions and predictive factors for mortality among children hospitalized with severe pneumonia in a rural developing country setting. $J$ Trop Pediatr. 2003; 49:327-32.

7. Rudan I. Epidemiology and etiology of childhood pneumonia. Bulletin of the World Health Organization. 2008; 86:408-16.

8. Rudan I, Pinto CB, Biloglav Z, Mulholland K, Campbell H. Epidemiology and etiology of childhood pneumonia. Bull World Health Organ. 2008; 86(5):408-16.

9. World Health Organization. Revised WHO classification and treatment of childhood pneumonia at health facilities. Geneva, Switzerland: World Health Organisation; 2014.

10. Harris M, Clark J, Coote N, Fletcher P, Harnden A, McKean $M$, et al. British Thoracic Society guidelines for the management of community acquired pneumonia in children: update 2011. Thorax, 66; 2011, ii1-23.
11. Bradley JS, Byington $\mathrm{CL}$, Shah SS, Alverson B, Carter ER, Harrison C, et al. The management of communityacquired pneumonia in infants and children older than 3 months of age: Clinical practice guidelines by the pediatric infectious diseases society and the infectious diseases society of America. Clinical Infectious Diseases. 2011; 53:e25-76.

12. WHO/UNICEF. Technical updates of the guidelines on the integrated management of childhood illness 2004. [Online]. [Cited on September 9, 2013]. Available at www.emro.who.int/CAH/pdf/imci_technical_ updates. pdf.

13. Zar HJ, Hanslo D, Tannenbaum E. Aetiology and outcome of pneumonia in human immune virus infected children hospitalized in South Africa. Acta Paediatr. 2001; 90:119-25.

14. Gratten M, Montgomery J. The bacteriology of acute pneumonia and meningitis in children in Papua New Guinea, assumptions, facts and technical strategies. PNG Med J. 1991; 34:185-98.

15. Zar HJ, Tannenbaun E, Hanslo D, Hussey G. Sputum induction as a diagnostic tool for communityacquired pneumonia in infants and young children in a high HIV prevalence area. Pediatr Pulmonol. 2003; 36:58-62.

16. Cotton MF, Burger PJ, Bodenstein WJ. Bacteraemia in children in the south-western Cape. A hospital based survey. S Afr Med J. 1992; 81:87-90.

17. Falade AG, Mulholland EK, Adegbola RA, Greenwood $\mathrm{BM}$. Bacterial isolates from blood and lung aspirate cultures in Gambian children with lobar pneumonia. Ann Tropical Pediatrics. 1997; 17:315.

18. Kabra SK, Lodha R, Broor S, Chaudhary R. Ghosh M, Maitreyi RS. Etiology of acute lower respiratory tract infection. Indian J Pediatr. 2003; 70:33.

19. Ali I, Butt MA (2017) Antibiotic susceptibility pattern of bacterial isolates from patients of respiratory tract infection at $\mathbf{4 3}$ centers in Punjab, Pakistan. Clin Exp Pharmacol 7:229. doi: 10.4172/2161-1459.1000229

20. Adegbola RA, Falade AG, Sam BE, Aidoo M, Baldeh I, Hazlett $D$, et al. The etiology of pneumonia in malnourished and well-nourished Gambian children. Pediatr Infect Dis J.1994; 13:975-82.

21. Korppi M. Community-acquired pneumonia in children: Issues in optimizing antibacterial treatment. Paediatr Drugs. 2003; 5:821-32.

22. McCracken GH. Diagnosis and management of pneumonia in children. Pediatr Infect Dis J. 2000; 19:924-8. 
23. Bradley JS. Management of community-acquired pediatric pneumonia in an era of increasing antibiotic resistance and conjugate vaccines. Pediatr Infect Dis J. 2002; 21:592-8.

24. Felmingham D, Canton R, Jenkins SG. Regional trends in beta-lactam, macrolide, fluoroquinolone and telithromycin resistance among Streptococcus pneumoniae isolates 2001-2004. J Infect. 2007; 55:111-8.
25. Atkinson M, Yanney M, Stephenson T, Smyth A. Effective treatment strategies for paediatric communityacquired pneumonia. Expert Opin Pharmacother. 2007; 8:1091-101.

26. Pelton SI, Hammerschlag MR. Overcoming current obstacles in the management of bacterial communityacquired pneumonia in ambulatory children. Clin Pediatr. 2005; 44:1-17.

\begin{tabular}{|c|c|c|c|}
\hline \multicolumn{4}{|c|}{ AUTHORSHIP AND CONTRIBUTION DECLARATION } \\
\hline Sr. \# & Author-s Full Name & Contribution to the paper & Author $=\mathbf{s}$ Signature \\
\hline 1 & Farman Ali & Conception and design of study. & $\underline{\underline{\Omega}}$ \\
\hline 2 & Rifaq Zeb & $\begin{array}{l}\text { Statistical expertise abstract and } \\
\text { article writing. }\end{array}$ & \\
\hline 3 & Farid Ullah & Drafting of the assembly of data. & \\
\hline 4 & Junaid Zeb & $\begin{array}{l}\text { Collection and assembly of } \\
\text { data, Data collection and } \\
\text { drafting of the article. }\end{array}$ & \\
\hline
\end{tabular}

